\title{
SEM, EDX and Magnetization Studies of Fe and Co Nano-particle Catalysts on Sol-gel Prepared Mesoporus $\gamma$-alumina.
}

\author{
Seetala V. Naidu ${ }^{\mathrm{a}}$, Upali Siriwardane ${ }^{\mathrm{b}}$, Akundi N. Murty ${ }^{\mathrm{a}}$, Naga Srivani Vegesna ${ }^{\mathrm{b}}$, James \\ Nwizugbu ${ }^{\mathrm{a}}$, Joseph Leonard and Charlene R. Jones ${ }^{\mathrm{a}}$. \\ a Department of Physics, Grambling State University, Grambling, LA 71245. \\ ${ }^{\mathrm{b}}$ Department of Chemistry, Louisiana Tech University, Ruston, LA 71272.
}

The synthesis of nano-particle $\mathrm{Fe}, \mathrm{Co}$ and $\mathrm{Fe} / \mathrm{Co}$ metal catalysts loaded on $\gamma$-alumina granules were achieved by a combined sol-gel/oil-drop method using metal ion solutions. Pure metal ion compositions of ion and cobalt, and mixed metal combinations were used. Comparative study of the ferromagnetic component of these reduced and post- reaction catalysts were undertaken to determine the efficiency of catalytic activation process and the subsequent changes in metal centers after the catalytic reactions.

The catalysts were characterized by powder X-ray diffraction (PXRD), differential thermal analysis (DTA), surface area analysis (BET), energy dispersive X-ray analysis (EDX) and gas chromatography (GC). Magnetization studies on reduced, $\mathrm{CO} / \mathrm{H}_{2}$ post-reaction catalyst in both gas and slurry phase were performed using vibrating sample magnetometer (VSM). SEM and PXRD confirmed the nano-particle nature of the catalyst and support, and X-ray diffraction indicates a higher porous structure and a mesoporus nature. Fig. 1 and 2 show uniform size of Fe/Co loaded $\gamma-$ granules and the porous nature. Magnified view of the granular surface showed nano-particles of $50 \mathrm{~nm}$ average size. The GC studies of nano-particle catalysts on sol-gel prepared mesoporus $\gamma$ alumina showed higher conversion rates compared to the conventional catalysts prepared by coprecipitation methods [1,2]. Catalyst with mixed metal Fe/Co compositions (prepared by sol-gel/oildrop) showed the best conversion rates for the syngas $\left(\mathrm{CO}+\mathrm{H}_{2}\right)$ to methane in the case of $12 \%$ metal solutions loading.

Fig. 3 shows the magnetic character of the catalysts obtained from VSM. The reduced catalysts show ferromagnetic nature of the $\mathrm{Fe}$ and $\mathrm{Co}$ in pure metallic form, while the post-reaction catalysts forming compounds during the reaction deactivated Fe and Co show almost paramagnetic nature. Table 1 summarizes the EDX and magnetization results. The pure metal $\%$ has been calculated from Fe and Co compositions from EDX and saturation magnetization $(\sigma)$ from VSM. Co is easily reduced and does not get deactivated compared to Fe. In mixed metal composition Co has higher metal loading than $\mathrm{Fe}$, which could be explained in terms of solubility of metal hydroxides formed during sol-gel preparation [3]. Even though the Co content is higher in mixed metal catalysts compared to pure Co catalysts (see EDX results), the activation of the catalyst during reduction is very poor in mixed metal catalysts as evidenced by very low pure metal $\%$. The interaction between $\mathrm{Fe}$ and $\mathrm{Co}$ and metal alloying could be the reason for the low activation in mixed metal catalysts.

1. L. C. Chao and R. P. Andres, J. of Colloid and Interface Sci. Vol.165 (1994) 290.

2. M.A Akundi, et al., IEEE Trans. on Magnetics, Vol. 37 (2001) 2929.

3. A.S. Kertes, Solubility Data Project. Chem. Int. 8, no. 5 (1986) 25-28.

* Work supported by the DOE contract \# DE-FG26-00NT40836. 


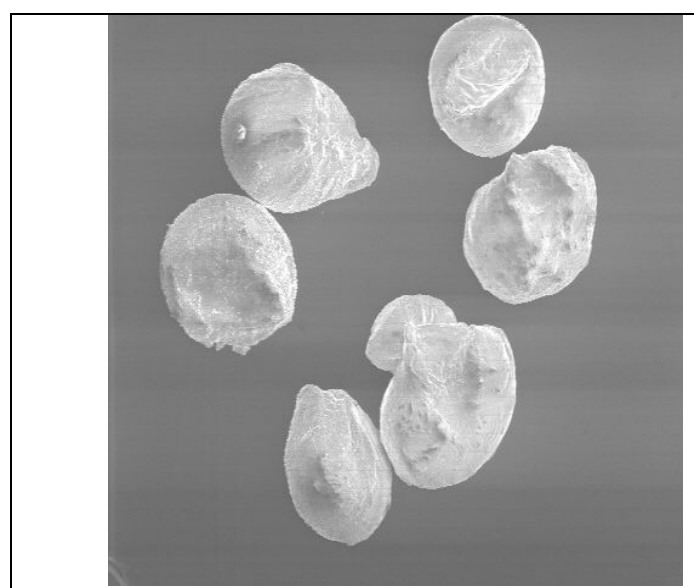

FIG. 1. SEM of $\gamma$-alumina granules at $50 \mathrm{X}$ Average granule size $\sim 1 \mathrm{~mm}$.

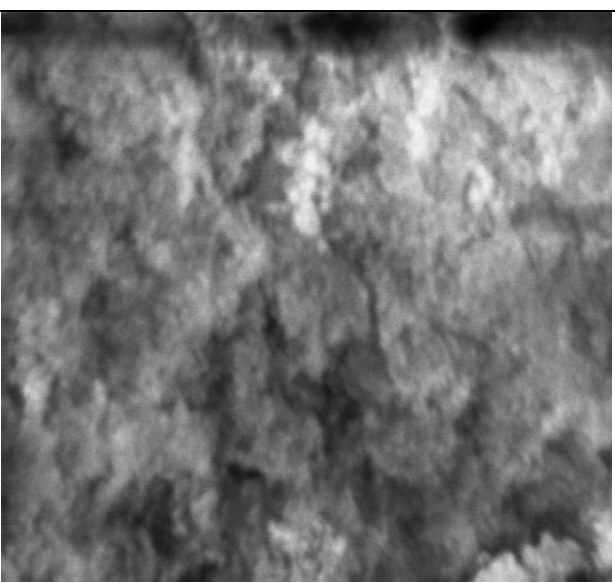

FIG. 2. SEM of granular surface at 60,000 X showing porous structure and $50 \mathrm{~nm}$ particles.

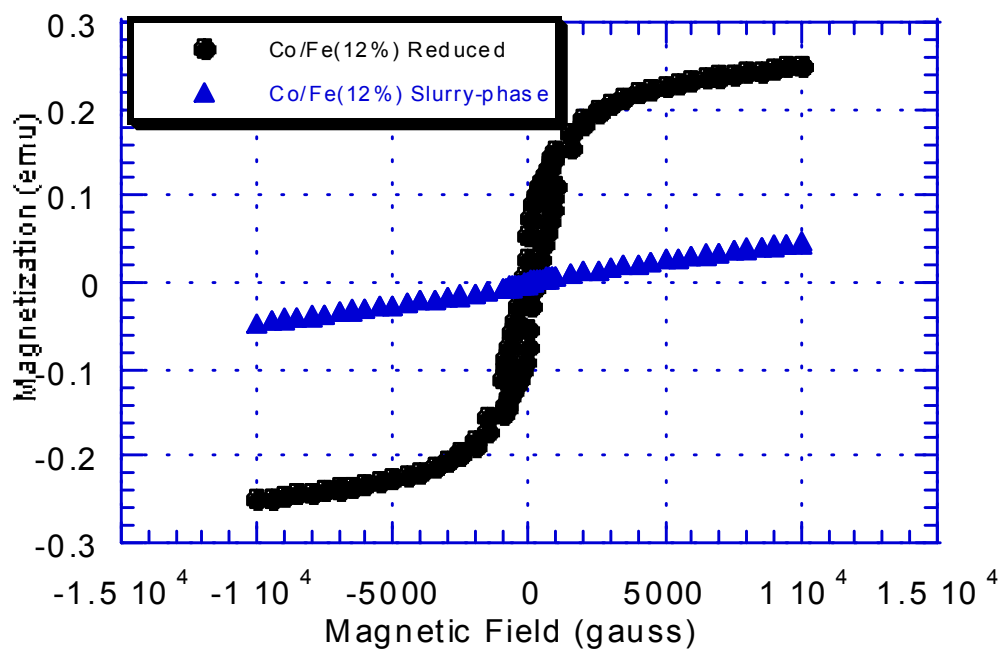

FIG. 3. Magnetization of Fe/Co (12\%) catalysts: $\bullet$ Reduced $\triangle$ After slurry-phase reaction.

Table 1. Energy Despersive X-ray Analysis and Magnetization Results

\begin{tabular}{|c|c|c|c|c|c|}
\hline Sample & Description & $\begin{array}{c}\sigma(\mathrm{emu} / \mathrm{g}) \\
\text { (VSM) }\end{array}$ & $\begin{array}{l}\text { Fe \% } \\
\text { (EDX) }\end{array}$ & $\begin{array}{l}\text { Co \% } \\
\text { (EDX) }\end{array}$ & $\begin{array}{l}\text { Pure } \\
\text { Metal \% }\end{array}$ \\
\hline \multicolumn{6}{|l|}{ Pure Co } \\
\hline Co(12\%) & Reduced & 5.94 & 0 & 3.9 & 94.35 \\
\hline $\mathrm{Co}(12 \%)$ & After reaction (gas-phase) & 4.40 & 0 & 3.9 & 69.84 \\
\hline $\operatorname{Co}(12 \%)$ & After reaction (slurry-phase) & 2.46 & 0 & 3.9 & 39.05 \\
\hline \multicolumn{6}{|l|}{ Pure Fe } \\
\hline $\mathrm{Fe}(12 \%)$ & Reduced & 0.71 & 2.1 & 0 & 15.57 \\
\hline $\mathrm{Fe}(12 \%)$ & After reaction (gas-phase) & 0.05 & 2.1 & 0 & 1.11 \\
\hline $\mathrm{Fe}(12 \%)$ & After reaction (slurry-phase) & 0.04 & 2.1 & 0 & 0.81 \\
\hline \multicolumn{6}{|c|}{ Mixed Metal } \\
\hline $\mathrm{Fe} / \mathrm{Co}(12 \%)$ & Reduced & 1.81 & 2.9 & 7.6 & 9.75 \\
\hline $\mathrm{Fe} / \mathrm{Co}(12 \%)$ & After reaction (gas-phase) & 1.56 & 2.9 & 7.6 & 8.41 \\
\hline $\mathrm{Fe} / \mathrm{Co}(12 \%)$ & After reaction (slurry-phase) & 0.05 & 2.9 & 7.6 & 0.28 \\
\hline
\end{tabular}

